\section{Chest MRI in patients with cystic fibrosis: a radiation-free method}

We read with great interest the well written manuscript by Mott et al, ${ }^{1}$ which reported their experience with CT for the detection of structural lung disease in infants and young children with cystic fibrosis (CF). They emphasised the importance of an early diagnosis because disease progression occurs over the course of 1 year in most cases. However, we would like to discuss some aspects of imaging studies in these patients.

CT is recognised as the gold standard for the assessment of morphological changes in the airways and lung parenchyma, ${ }^{2}$ and is currently the only reliable imaging modality for the diagnosis and monitoring of early CF lung disease. ${ }^{3}$ However, compared with other methods, chest CT exposes patients to much higher radiation doses. ${ }^{4}$ Considering the necessity of lifelong repeated imaging studies in patients with CF, the cumulative radiation dose reached with CT has restricted its use, especially for short-term follow-up purposes. $^{4}$

MRI has therefore been established as a radiation-free alternative to CT for the assessment of lung disease in patients with CF. In addition to morphological imaging, this modality enables the visualisation and regional measurement of functional qualities of the lung. MRI of the chest was proposed as a potential imaging alternative in patients with CF in the late 1980s, although at that time, MRI technology was not capable of producing results comparable to those of CT. In the last decade, new technologies and strategies have been implemented to overcome the inherent difficulties of lung MRI. The introduction of parallel imaging in clinical practice has enabled more rapid image acquisition, substantially improving temporal and/or spatial resolution. ${ }^{5}$ Previous studies have proven that MRI is comparable to CT for the detection of morphological changes in the lungs of patients with CF, without requiring the use of ionising radiation. Furthermore, MRI was shown to be superior to CT for the assessment of functional changes in the lung. ${ }^{5}$ In this setting, we would thus like to highlight the importance of MRI in monitoring lung abnormalities in patients with CF.

\section{Bruno Hochhegger, ${ }^{1}$ Klaus L Irion, ${ }^{2}$ Edson Marchiori}

'Department of Radiology, Rio de Janeiro Federal
University, Porto Alegre, Rio Grande do Sul, Brazil
${ }^{2}$ Department of Radiology, Royal Liverpool University
Hospital, Liverpool, UK, 'Department of Radiology,
Liverpool Heart and Chest Hospital, Liverpool, UK
${ }^{3}$ Federal University of Rio de Janeiro, Rio de Janeiro,
Brazil

Correspondence to Professor Bruno Hochhegger, Department of Radiology, Rio de Janeiro Federal University, rua 24 de outubro 925, Porto Alegre, Rio Grande do Sul 9510002, Brazil; brunohochhegger@ gmail.com

\section{Competing interests None.}

Provenance and peer review Not commissioned; externally peer reviewed.

To cite Field JK, Baldwin D, Brain K, et al. Thorax 2013, 68, 105-106.

Accepted 17 September 2012

Published Online First 12 October 2012

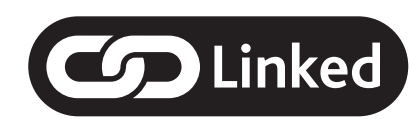

http://dx.doi.org/10.1136/thoraxjnl-2012-202670

Thorax 2013;68:105-106.

doi:10.1136/thoraxjnl-2012-202232 


\section{REFERENCES}

1 Mott LS, Park J, Murray CP, et al. Progression of early structural lung disease in young children with cystic fibrosis assessed using CT. Thorax 2012;67:509-16.

2 Davis SD, Brody AS, Emond MJ, et al. Endpoints for clinical trials in young children with cystic fibrosis. Proc Am Thorac Soc 2007;4:418-30.

3 Tiddens HA. Chest computed tomography scans should be considered as a routine investigation in cystic fibrosis. Paediatr Respir Rev 2006;7:202-8.

4 de Jong PA, Mayo JR, Golmohammadi K, et al. Estimation of cancer mortality associated with repetitive computed tomography scanning. Am J Respir Crit Care Med 2006;173:199-203.

5 Puderbach M, Eichinger $M$. The role of advanced imaging techniques in cystic fibrosis follow-up: is there a place for MRI? Pediatr Radiol 2010;40:844-9. 